\title{
Novel concepts and strategies in skull base reconstruction after endoscopic endonasal surgery
}

\section{Domenico Solari ${ }^{1}$, Ida Papallo², Lorenzo Ugga ${ }^{2}$, Luigi M. Cavallo ${ }^{1}$, Ilaria Onofrio ${ }^{3}$, Renato Cuocolo², Giovanni Improta ${ }^{4}$, Arturo Brunetti ${ }^{2}$, Massimo Martorelli ${ }^{5}$, Antonio Gloria ${ }^{6}$, Paolo Cappabianca ${ }^{1}$, Teresa Russo ${ }^{6}$}

${ }^{1}$ Division of Neurosurgery, Department of Neurosciences, Reproductive and Odontostomatological Sciences, University of Naples Federico II, Naples, Italy

2 Department of Advanced Biomedical Sciences, University of Naples Federico II, Naples, Italy

${ }^{3}$ Department of Neurosciences, Reproductive and Odontostomatological Sciences, University of Naples Federico II, Naples, Italy

${ }^{4}$ Department of Public Health, University of Naples Federico II, Naples, Italy

${ }^{5}$ Department of Industrial Engineering, Fraunhofer JL IDEAS, University of Naples Federico II, Naples, Italy

${ }^{6}$ Institute of Polymers, Composites and Biomaterials - National Research Council of Italy, Naples, Italy

\section{ABSTRACT}

Recently, a variety of craniofacial approaches has been adopted to enter the skull base, including the endonasal endoscopic technique. An effective watertight technique, the reconstruction can be performed using different materials, both autologous and non-autologous, individually or combined in a multilayer fashion. The current study focuses on the development of new advanced devices and techniques that help to reduce the postoperative cerebrospinal fluid leak rate. Additive manufacturing allows the design of devices with tailored structural and functional features, as well as injectable semi-interpenetrating polymer networks and composites; therefore, specific mechanical/rheological and injectability studies are valuable. Accordingly, we propose new additive manufactured and injectable devices.

\section{Section: RESEARCH PAPER}

Keywords: endoscopic endonasal surgery; skull base reconstruction; CSF leakage; reverse engineering; additive manufacturing; design of injectable systems Citation: Domenico Solari, Ida Papallo, Lorenzo Ugga, Luigi M. Cavallo, Ilaria Onofrio, Renato Cuocolo, Giovanni Improta, Arturo Brunetti, Massimo Martorelli, Antonio Gloria, Paolo Cappabianca, Teresa Russo, Novel concepts and strategies in skull base reconstruction after endoscopic endonasal surgery, Acta IMEKO, vol. 9, no. 4, article 9, December 2020, identifier: IMEKO-ACTA-09 (2020)-04-09

Section Editor: Leopoldo Angrisani, University of Naples Federico II, Italy

Received November 4, 2019; In final form August 5, 2020; Published December 2020

Copyright: This is an open-access article distributed under the terms of the Creative Commons Attribution 3.0 License, which permits unrestricted use, distribution, and reproduction in any medium, provided the original author and source are credited.

Corresponding authors: Domenico Solari, e-mail: domenico.solari@unina.it, Ida Papallo, e-mail: i.papallo89@gmail.com

\section{INTRODUCTION}

The skull base is located between the brain and the extracranial compartment and consists of several anatomical structures.

From an anatomical and surgical point of view, the skull base represents one of the most complex areas of the human body.

It is reported that a broad variety of lesions, either neoplastic or not, may arise primarily from this area or, subsequently, involve it. The surgical management of these lesions can be extremely difficult, especially of deep-seated lesions, despite a variety of innovative craniofacial approaches that have been adopted to access the entire skull base in recent decades $0-[9]$.
Additionally, it should be underlined that tissue disruption and neurovascular manipulation often characterise the access routes to the skull base, increasing perioperative morbidity and/or mortality rates.

The surgical advances and technological innovations, together with the progress in diagnostic imaging techniques and the intraoperative neuronavigational systems, have progressively reduced the surgical invasiveness of the skull base approaches.

Specifically, a trans-sphenoidal technique was developed for the treatment of lesions previously amenable only to a transcranial route. In fact, over the past few years, the endonasal endoscopic route has been considered as a viable corridor to access first the sellar region, and then the surrounding areas. Presently, this route represents a suitable approach for several skull base lesions [10]-[12]. 
These surgical refinements and technological advances, together with an increasing comprehension of the region's anatomy, have led to a revolution in skull base surgery [13].

In further detail, the main advantage of skull base surgery performed through the nose, using an endoscope, is the direct visualisation of the neurovascular structures of several areas of the skull base while minimising brain displacement and manipulation.

The use of an endoscope allows for a wider and multiangled close-up view of the surgical field. As a result, patients treated with this approach may benefit in terms of early discharge, reduced postoperative morbidity, and a faster return to work [14].

However, the main issue of this approach lies in the reconstruction, as a consequence of a higher risk of postoperative cerebrospinal fluid (CSF) leakage in comparison with the conventional transcranial method [15].

The removal of a skull base lesion via the endonasal route requires a wider osteo-dural opening and, especially, extensive opening of the arachnoid cisterns and/or, sometimes, the third ventricle. Consequently, a large communication between the septic cavity (i.e. the sinonasal tract) and the sterile intradural compartment is created.

An effective watertight closure is fundamental to isolating the intracranial cavity for restoration of the natural intra and extradural compartment division, to prevent postoperative CSF leakage and further complications (i.e. brain herniation, meningitis, tension pneumocephalus) [16].

Skull base reconstruction after extended endoscopic endonasal surgery should be optimised taking into account some crucial points (i.e. isolation of the intradural compartment from the sinonasal tract, water and airtight closure, obliteration of dead spaces, promotion of the healing process, preservation of function and cosmesis, and management of the risk factors of increased intracranial pressure) [15],[17],[18].

Accordingly, the reconstruction can be performed using different devices that consist of autologous grafts and nonautologous materials, individually or combined in a multilayer strategy.

The purported multilayer techniques have to deal mostly with the major issues of the irregular shape of both bony and dural defect boundaries, and the presence of optic nerves, internal carotid arteries, and the neurovascular structures of the cavernous sinus, surrounding them. Furthermore, the removal of the tuberculum sellae and of the posterior part of the planum sphenoidale, along with the floor of the sella, creates a defect that does not lie on a flat plane. For these reasons, especially in the cases with a very large skull base opening, a semisolid buttress - adopted to sustain the dural foil - does not adhere properly.

Thus far, the recent trend is moving toward the use of autologous materials [19]-[21].

Autologous grafts can interact with the surrounding structures of the osteo-dural defect, favouring the migration of fibroblasts and, consequently, a complete recovery.

Clearly, each component plays its specific role. Cartilage and bone offer support, whereas the mucosa provides the matrix for the tissue vascularisation.

The harvesting of a nasoseptal flap is considered to be one of the most effective techniques: it is able to bolster the skull base closure, ensuring the isolation of the surgical field, and plays an important role in reducing the CSF leak rate after endoscopic skull base surgery [22].
Nevertheless, it should be performed only in cases of wide skull base defects, as it may lead to nasal morbidity [19],[23].

The development of novel closure techniques and the availability of reliable reconstructive materials may contribute to reducing the postoperative CSF leak, which represents one of the most feared complications of this type of surgical procedure [22],[24],[25].

In the last few months, we have modified our reconstruction method according to the concept of ' $3 \mathrm{~F}$ ', each addressing a different compartment of the defect to be sealed. The first ' $F$ ' stands for autologous fat, to be used as a cork stopper across the intra-extradural space; the second ' $F$ ' refers to the nasoseptal flap, used to cover the skull base defect - we harvest it at the end of the surgical procedure; and, finally, the third ' $\mathrm{F}$ ' represents our idea of 'flash' patient mobilisation out of the bed [26].

The major advantages arise from the possibility of moulding the fat inside the surgical cavity, having it pierce the entire diameter of the breach and, above all, fit and fill the outer shady areas, namely the irregular contours at the level of the tuberculum sellae and the optic canals [26].

In this context, further efforts are needed to develop novel strategies and devices for reducing the CSF leak rates after endoscopic skull base surgery, as well as the post-operative patient discomfort and morbidity.

Moreover, benefiting from the development of advanced technologies [27] and methodologies of analysis [28]-[31] in different fields, innovative systems may also be designed for biomedical applications.

The research has been driven toward the engineering of materials [32],[33] and biomedical devices with improved and tailored functional properties [34],[35].

Novel and multifunctional devices may be developed in the form of injectable or solid systems, according to the specific application and the surgical approach.

Concerning the skull base reconstruction after endoscopic endonasal surgery, intriguing strategies would involve advances in the development of injectable semi-interpenetrating polymer networks (semi-IPNs) and composites, computer-aided design (CAD), reverse engineering, and 3D additive manufactured devices with controlled architectures and mechanical properties [34],[35].

The current research is focused on the development of novel approaches and devices, aiming at preventing the postoperative CSF leakage in skull base reconstruction after endoscopic endonasal surgery, which represents one of the most feared complications related to this procedure.

A design strategy was proposed involving the use of an injectable tool as a filling system and a 'solid' customised device as a closure system for skull base defects.

\section{MATERIALS AND METHODS}

The semi-IPNs were prepared by promoting the polymer network formation. Natural and synthetic polymers were employed and also properly modified. Micro/nanoparticles were also used as reinforcement.

The selection of the system components was made with the aim of promoting a clinical translation of the injectable devices as dura mater substitutes and sealant systems able to reduce the risk of CSF leakage. 
A rheometer (Bohlin Gemini; Malvern Instruments, Malvern, UK) equipped with parallel-plate geometry was used to evaluate the viscoelastic properties of the materials at $37^{\circ} \mathrm{C}$.

To determine the linear viscoelastic region, strain sweep tests were carried out at a fixed oscillation frequency.

Small amplitude oscillatory shear tests were performed, and the frequency varied from 0.01 to $2 \mathrm{~Hz}$.

The storage modulus $\left(G^{\prime}\right)$ and the loss modulus $\left(G^{\prime}\right)$ were evaluated as follows:

$$
\begin{aligned}
G^{\prime} & =\frac{\tau_{0}}{\gamma_{0}} \cos \delta \\
G^{\prime \prime} & =\frac{\tau_{0}}{\gamma_{0}} \sin \delta
\end{aligned}
$$

with $\delta$ representing the phase shift between the input and output signals, whereas $\gamma_{0}$ and $\tau_{0}$ represent the strain and stress amplitudes, respectively.

Different clinical needles were considered, and the effect of the injection on the viscoelastic properties was analysed, as it plays a crucial role in the design of injectable systems.

Steady shear measurements were carried out, and viscosity as a function of shear rate was evaluated at $37^{\circ} \mathrm{C}$ (Figure 1). The shear rate ranged from 0.01 to $10 \mathrm{~s}^{-1}$.

To simulate clinical practice, injectability tests were also performed using an INSTRON 5566 testing machine.

By contrast, image capture and analysis techniques were used to generate 3D virtual models of the skull base defects.

In particular, 3D reconstruction of the skull base region and defects was performed using computed tomography (CT) and a dedicated software.

The model of a region of the skull base and customised devices for the defects were manufactured by fused deposition modelling using a $3 \mathrm{D}$ printer.

In particular, Z-Glass filament was used to manufacture models of a skull base region, whereas a very durable and flexible material certified for medical use (BioFlex, FILOALFA) was employed for the fabrication of customised closure devices for the skull base defects.

\section{RESULTS}

Starting from some basic concepts and principles, novel strategies may be proposed towards the design of injectable systems and additively manufactured devices for skull base reconstruction after endoscopic endonasal surgery.

Recent literature stresses the important role of reverse engineering [36]-[39], computer-aided design (CAD), and finite element analysis [40]-[43], as well as the potential of pushing the research toward the development of design strategies and methodologies of analysis in different fields of application [44][47].

The strategy related to the design of injectable semi-IPNs and composites with tailored properties has benefited from specific rheological/mechanical and injectability studies [48].

Injectable devices can also be developed through the combination of conventional methods and additive manufacturing techniques.

Some examples of rheological results obtained from analyses performed on semi-IPNs consisting of different materials are reported below. The materials are not specified, the aim being only to stress the importance and the role of the viscoelastic properties and the flow behaviour in the design of the proposed

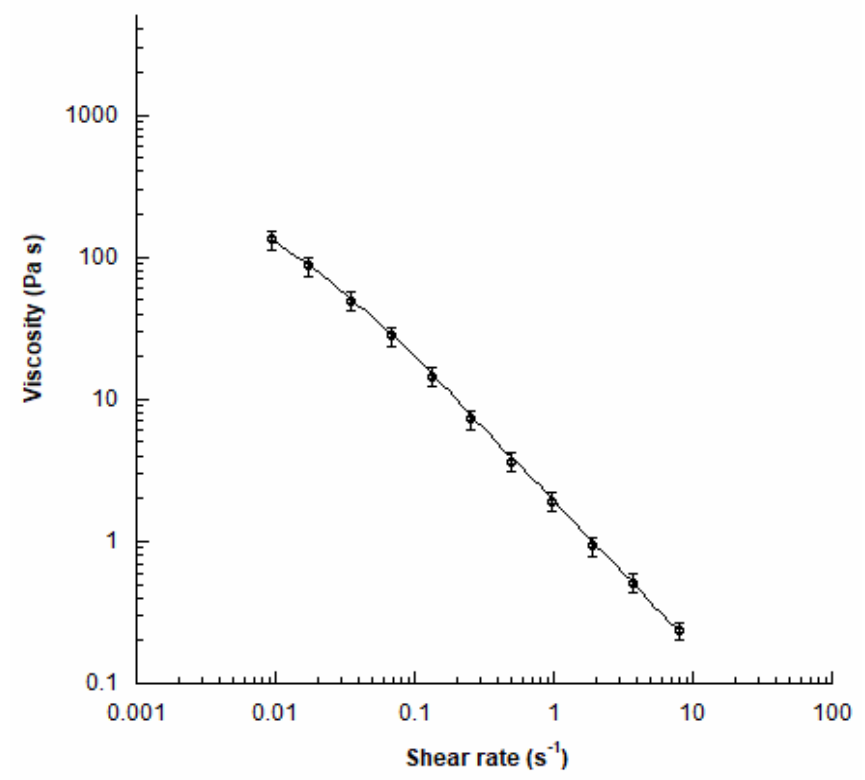

Figure 1. Example of viscosity as a function of shear rate for the developed semi-IPNs. The data are reported as the mean value; the error bar represents the standard deviation.

systems, as it is widely reported [48] that the potential to tailor their rheological characteristics clearly depends on the employed material combinations.

An example of one of the mechanical spectra achieved for the developed semi-IPNs is reported in Figure 2.

The $G$ 'values were always higher than the $G$ ' values in the analysed frequency range (Figure 2).

Furthermore, the presence of micro/nanoparticles generally improved both viscoelastic moduli, until a threshold limit value was reached for the particle concentration.

Figure 1 reports typical values of the viscosity as a function of the shear rate obtained for some engineered semi-IPNs.

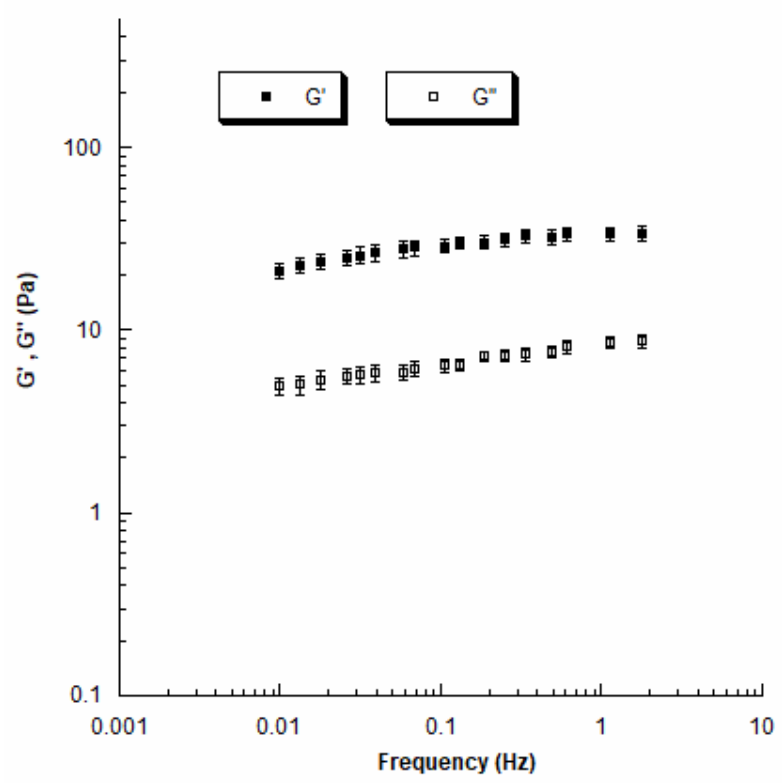

Figure 2. Example of the storage modulus $\left(G^{\prime}\right)$ and the loss modulus $\left(G^{\prime \prime}\right)$ as a function of the frequency for the developed semi-IPNs. The data are reported as the mean value; the error bar represents the standard deviation. 

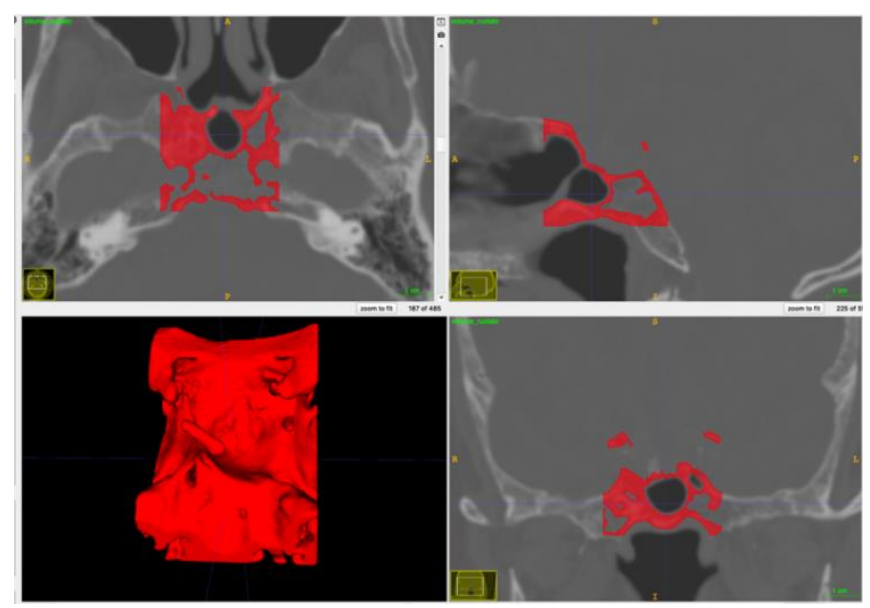

Figure 3. Results from image capture and analysis - skull base region.

The results showed that the viscosity decreased with the increasing shear rate (shear thinning behaviour), thus suggesting the possibility of injecting the developed materials.

Load-displacement curves were obtained from injectability tests. At low displacements, the curves obtained for the semiIPNs showed a linear region until the load reached a maximum value. Successively, the load sharply dropped to a plateau value as the displacement further increased. At the end of the plateaulike region, the material was completely injected.

The obtained values for the maximum and plateau loads were in the range of $6.6-3.7 \mathrm{~N}$ and $2.0-0.9 \mathrm{~N}$, respectively, depending on the clinical needle employed and the material composition.

By contrast, additive manufacturing techniques offer the opportunity of developing customised devices with complex geometry.

Additive manufactured devices with several architectural features can be fabricated by the 3D fibre deposition technique/fused deposition modelling (FDM) [34],[35].

Starting from CT analysis, the surgical approach and the creation of a bone defect (i.e., cavity) were planned (Figure 3 and Figure 4).

Virtual models of a region of the skull base without and with the defect (Figure 5 and Figure 6), as well as of the customised closure device (Figure 7) were created.
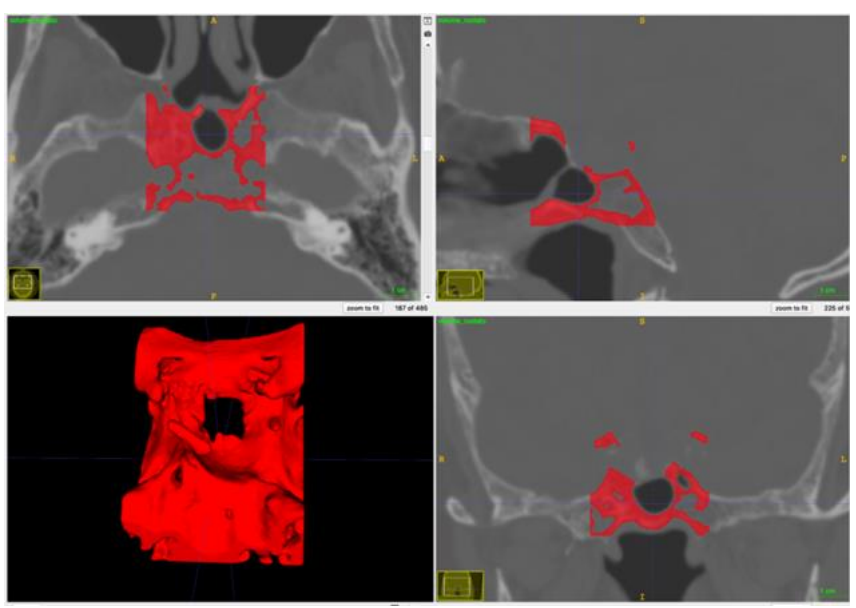

Figure 4. Results from the image capture and analysis: planning of the surgical approach and preparation of a cavity as a skull base defect.
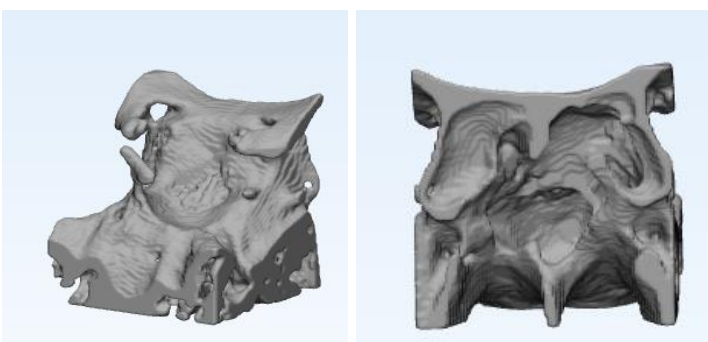

Figure 5. 3D reconstruction of a skull base region.
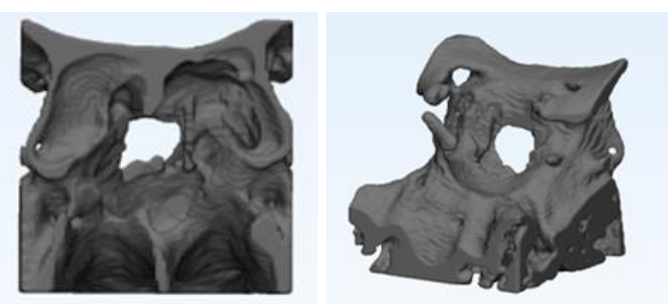

Figure 6. 3D reconstruction of a skull base region with the created defect.

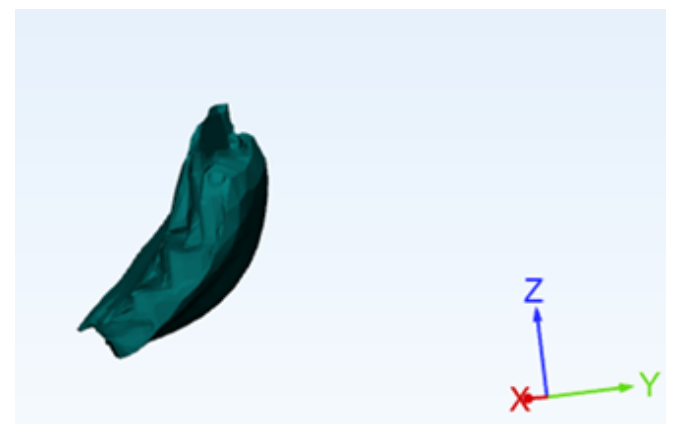

Figure 7. 3D model of the customised device as a closure system for the skull base defect.

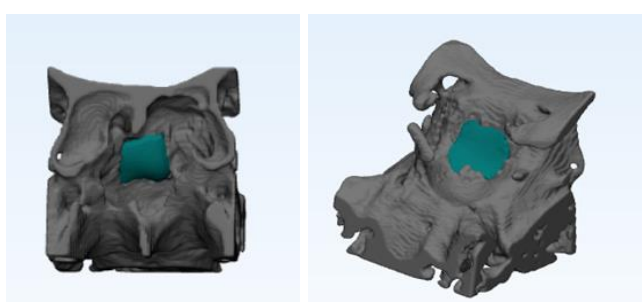

Figure 8. 3D model of the device closing the skull base defect - different views. Feasibility assessment of the proposed technical solutions.

Initially starting from the shape and size of the defect, the geometry of the closure device was appropriately designed to be fitted in the cavity to prevent CSF leakage.

The feasibility of the proposed technical solutions was first assessed through virtual models (Figure 8).

Additive manufactured models of a skull base region with the defect were developed using Z-Glass filament (Figure 9).

$3 \mathrm{D}$ customised devices with appropriate flexibility were also manufactured by FDM, using BioFlex filament, as a closure system for the created skull base defect (Figure 10).

In comparison with conventional fabrication methods, additive manufacturing techniques allow strict control of the structural features and, consequently, of the properties of the devices, satisfying all the requirements [34],[35].

The customised closure devices were suitably developed to provide high flexibility and relatively high strength, according to the specific application. 

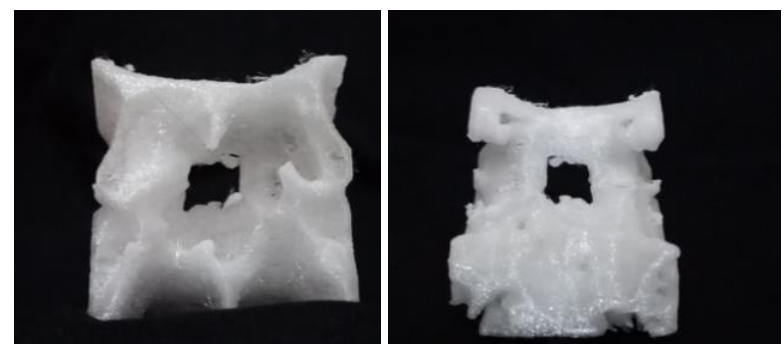

Figure 9. 3D additive manufactured model of a skull base region with the created defect - different views.
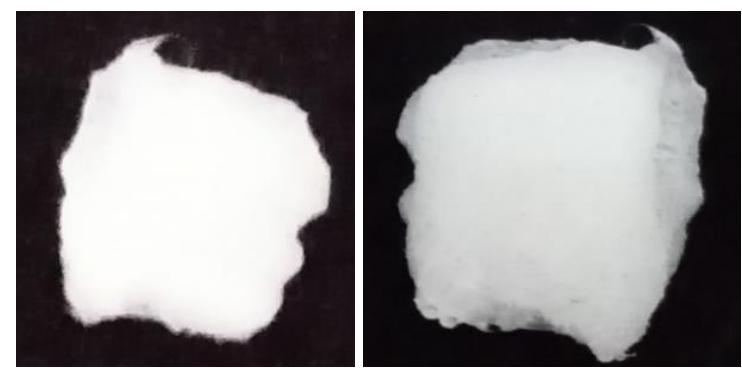

Figure 10. 3D additive manufactured model of the closure device - different views.

The physical models were used to simulate clinical practice, and the feasibility of the proposed approach was consequently demonstrated (Figure 11).
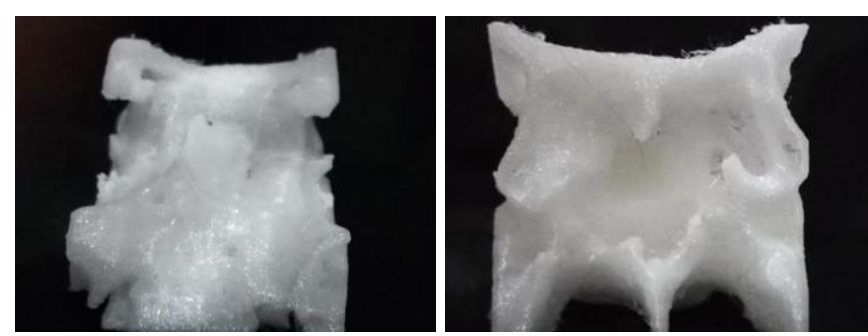

Figure 11. 3D physical model of the device closing the skull base defect different views. Feasibility assessment of the proposed technical solutions.

\section{CONCLUSIONS}

An insight into the development of novel strategies and devices for skull base defects was provided by integrating rheological/mechanical concepts, image capture and analysis techniques, the CAD approach, and additive manufacturing.

Specifically, a systematic study of the design of multifunctional systems in the form of injectable tools and 'solid' customised devices was reported in the current research.

The focus was set on the importance of viscoelastic properties and the flow behaviour of materials in the case of injectable systems, as well as on the potential to start from the geometry of skull base defects to design additive manufactured closure devices with tailored properties (i.e. flexibility, strength) for the skull base reconstruction after endoscopic endonasal surgery.

$3 \mathrm{D}$ virtual and physical models allowed the possibility of planning the surgery, as well as assessing the feasibility of the proposed technical solutions.

\section{REFERENCES}

[1] R. Fahlbusch, W. Schott, Pterional surgery of meningiomas of the tuberculum sellae and planum sphenoidale: surgical results with special consideration of ophthalmological and endocrinological outcomes, Journal of neurosurgery (2002) 96(2), pp.235-243. DOI: https://doi.org/10.3171/jns.2002.96.2.0235

[2] T. Javed, L. N. Sekhar, Surgical management of clival meningiomas, Acta Neurochirurgica Supplementum 53 (1991), pp. 171-182. DOI: https://doi.org/10.1007/978-3-7091-9183-5 28

[3] T. Kawase, R. Shiobara, S. Toya, Anterior transpetrosaltranstentorial approach for sphenopetroclival meningiomas: surgical method and results in 10 patients, Neurosurgery 28(6) (1991), pp. 869-875, discussion pp. 875-866.

[4] D. A. Lang, G. Neil-Dwyer, F. Iannotti, The suboccipital transcondylar approach to the clivus and cranio-cervical junction for ventrally placed pathology at and above the foramen magnum, Acta Neurochirurgica 125(1-4) (1993), pp. 132-137.

DOI: https://doi.org/10.1007/BF01401840

[5] J. D. MacDonald, P. Antonelli, A. L. Day, The anterior subtemporal, medial transpetrosal approach to the upper basilar artery and ponto-mesencephalic junction, Neurosurgery (1998) 43(1), pp. 84-89.

DOI: https://doi.org/10.1097/00006123-199807000-00054

[6] E. Miller, H. A. Crockard, Transoral transclival removal of anteriorly placed meningiomas at the foramen magnum, Neurosurgery 20(6) (1987), pp. 966-968.

DOI: https://doi.org/10.1227/00006123-198706000-00026

[7] M. Nakamura, M. Samii, Surgical management of a meningioma in the retrosellar region, Acta neurochirurgica 145(3) (2003), pp. 215-219, discussion pp. 219-220.

DOI: https://doi.org/10.1007/s00701-002-1053-z

[8] R. Reisch, M. Bettag, A. Perneczky, Transoral transclival removal of anteriorly placed cavernous malformations of the brainstem, Surgical Neurology 56(2) (2001), pp. 106-115 discussion pp. 115106.

DOI: https://doi.org/10.1016/s0090-3019(01)00529-8

[9] V. Seifert, A. Raabe, M. Zimmermann, Conservative (labyrinthpreserving) transpetrosal approach to the clivus and petroclival region--indications, complications, results and lessons learned, Acta Neurochirurgica 145(8) (2003), pp. 631-642, discussion p. 642.

DOI: https://doi.org/10.1007/s00701-003-0086-2

[10] P. Cappabianca, L. M. Cavallo, F. Esposito, O. De Divitiis, A. Messina, E. De Divitiis, Extended endoscopic endonasal approach to the midline skull base: the evolving role of transsphenoidal surgery, Adv Tech Stand Neurosurg 33 (2008), pp. 151-199. DOI: https://doi.org/10.1007/978-3-211-72283-1 4

[11] G. Zada, D. F. Kelly, P. Cohan, C. Wang, R. Swerdloff, Endonasal transsphenoidal approach for pituitary adenomas and other sellar lesions: an assessment of efficacy, safety, and patient impressions, J Neurosurg 98(2) (2003), pp. 350-358. DOI: https://doi.org/10.3171/ins.2003.98.2.0350

[12] L. M. Cavallo, P. Cappabianca, A. Messina, F. Esposito, L. Stella, E. de Divitiis, M. Tschabitscher, The extended endoscopic endonasal approach to the clivus and cranio-vertebral junction: anatomical study, Childs Nerv Syst 23(6) (2007), pp 665-671. DOI: https://doi.org/10.1007/s00381-007-0332-7

[13] D. Solari, C. Chiaramonte, A. Di Somma, G. Dell'Aversana Orabona, M. de Notaris, F. Flavio Angileri, L. M. Cavallo, S. Montagnani, M. Tschabitscher, P. Cappabianca, Endoscopic anatomy of the skull base explored through the nose, World Neurosurg 82(6 Suppl) (2014), pp. S164-S170. DOI: https://doi.org/10.1016/j.wneu.2014.08.005

[14] P. Cappabianca, L. M. Cavallo, D. Solari, V. Stagno, F. Esposito, M. de Angelis, Endoscopic endonasal surgery for pituitary adenomas, World Neurosurg (2014) 82(6 Suppl), pp. S3-S11. DOI: https://doi.org/10.1016/j.wneu.2014.07.019 
[15] F. Esposito, J. R. Dusick, N. Fatemi, D. F. Kelly, Graded repair of cranial base defects and cerebrospinal fluid leaks in transsphenoidal surgery, Neurosurgery 60(4 Suppl 2) (2007), pp.295-303, discussion pp. 303-304.

DOI: https://doi.org/10.1227/01.NEU.0000255354.64077.66

[16] R. L. Carrau, C. H. Snyderman, A. B. Kassam, The management of cerebrospinal fluid leaks in patients at risk for high-pressure hydrocephalus, Laryngoscope 115(2) (2005), pp. 205-212. DOI: https://doi.org/10.1097/01.mlg.0000154719.62668.70

[17] M. de Angelis, P. Cappabianca, Gutta cavat lapidem: the reconstruction of the skull base after endoscopic endonasal surgery, World Neurosurg 83(2) (2015), pp. 136-137.

DOI: https://doi.org/10.1016/i.wneu.2014.06.050

[18] M. Turri-Zanoni, J. Zocchi, A. Lambertoni, M. Giovannardi, A. Karligkiotis, P. Battaglia, D. Locatelli, P. Castelnuovo, Endoscopic endonasal reconstruction of anterior skull base defects: what factors really affect the outcomes?, World Neurosurg 116 (2018), pp. e436-e443. DOI: https://doi.org/10.1016/j.wneu.2018.04.225

[19] M. R. Patel, R. N. Shah, C. H. Snyderman, R. L. Carrau, A. V. Germanwala, A. B. Kassam, A. M. Zanation, Pericranial flap for endoscopic anterior skull-base reconstruction: clinical outcomes and radioanatomic analysis of preoperative planning, Neurosurgery 66(3) (2010), pp. 506-512, discussion p. 512. DOI: https://doi.org/10.1227/01.NEU.0000365620.59677.FF

[20] H. Hasegawa, M. Shin, K. Kondo, N. Saito, Reconstruction of dural defects in endoscopic transnasal approaches for intradural lesions using multilayered fascia with a pressure-control spinal drainage system, World Neurosurg 114 (2018), pp. e1316-e1324. DOI: https://doi.org/10.1016/i.wneu.2018.03.209

[21] M. R. Patel, R. J. Taylor, T. G. Hackman, A. V. Germanwala, D. Sasaki-Adams, M. G. Ewend, A. M. Zanation, Beyond the nasoseptal flap: outcomes and pearls with secondary flaps in endoscopic endonasal skull base reconstruction, Laryngoscope 124(4) (2014), pp. 846-852. DOI: https://doi.org/10.1002/lary.24319

[22] G. Hadad, L. Bassagasteguy, R. L. Carrau, J. C. Mataza, A. Kassam, C. H. Snyderman, A. Mintz, A novel reconstructive technique after endoscopic expanded endonasal approaches: vascular pedicle nasoseptal flap, Laryngoscope 116(10) (2006), pp.1882-1886.

DOI: https://doi.org/10.1097/01.mlg.0000234933.37779.e4

[23] B. D. Thorp, S. B. Sreenath, C. S. Ebert, A. M. Zanation, Endoscopic skull base reconstruction: a review and clinical case series of 152 vascularized flaps used for surgical skull base defects in the setting of intraoperative cerebrospinal fluid leak, Neurosurg Focus 37(4) (2014) E4.

DOI: https://doi.org/10.3171/2014.7.FOCUS14350

[24] A. Kassam, R. L. Carrau, C. H. Snyderman, P. Gardner, A. Mintz, Evolution of reconstructive techniques following endoscopic expanded endonasal approaches, Neurosurg Focus 19(1): (2005) E8. DOI: https://doi.org/10.3171/foc.2005.19.1.9

[25] A. Conger, F. Zhao, X.Wang, A. Eisenberg, C. Griffiths, F. Esposito, R. L. Carrau, G. Barkhoudarian, D. F. Kelly, Evolution of the graded repair of CSF leaks and skull base defects in endonasal endoscopic tumor surgery: trends in repair failure and meningitis rates in 509 patients. J Neurosurg 130(3) (2018), pp. 861-875.

DOI: https://doi.org/10.3171/2017.11.JNS172141

[26] L. M. Cavallo, D. Solari, T. Somma, P. Cappabianca, The 3F (fat, flap, and flash) technique for skull base reconstruction after endoscopic endonasal suprasellar approach, World Neurosurg 126 (2019), pp.439-446.

DOI: https://doi.org/10.1016/i.wneu.2019.03.125

[27] F. Bonavolontà, A. Tedesco, R. Schiano Lo Moriello, A. Tufano, Enabling wireless technologies for industry 4.0: State of the art, In: Proc. of IEEE International Workshop on Measurement and Networking, M \& N 2017, Naples, Italy, 27-29 September 2017, pp. 1-5.

DOI: https://doi.org/10.1109/IWMN.2017.8078381

[28] F. Bonavolontà, M. D'Arco, G. Ianniello, A. Liccardo, R. Schiano Lo Moriello, L. Ferrigno, G. Miele, On the suitability of compressive sampling for the measurement of electrical power quality, Proc. of Instrumentation and Measurement Technology Conference (I2MTC), Minneapolis, USA, 6-9 May 2013, pp. 126131.

DOI: https://doi.org/10.1109/I2MTC.2013.6555395

[29] L. Angrisani, A. Arpaia, F. Bonavolontà, M. Conti, A. Liccardo, LoRa protocol performance assessment in critical noise conditions, Proc. of IEEE International Forum on Research and Technologies for Society and Industry (RTSI), Modena, Italy, 1113 September 2017.

DOI: https://doi.org/10.1109/RTSI.2017.8065952

[30] C. Landi, A. Liccardo, N. Polese, Remote laboratory activities to support experimental session for undergraduate measurements courses, Proc. of IEEE Instrumentation and Measurement Technology Conference (IMTC), Sorrento, Italy, 24-27 April 2006, pp. 851-856. DOI: https://doi.org/10.1109/IMTC.2006.328232

[31] L. Angrisani, F. Bonavolontà, R. Schiano Lo Moriello, A. Andreone, R. Casini, G. Papari, D. Accardo, First steps towards an innovative compressive sampling based-THz imaging system for early crack detection on aereospace plates, Proc. of IEEE Metrology for Aerospace (MetroAeroSpace), Benevento, Italy, 29-30 May 2014, p. 488-493.

DOI: https://doi.org/10.1109/MetroAeroSpace.2014.6865974

[32] L. Russo, A. Gloria, T. Russo, U. D'Amora, F. Taraballi, R. De Santis, L. Ambrosio, F. Nicotra, L. Cipolla, Glucosamine grafting on poly( $\varepsilon$-caprolactone): a novel glycated polyester as a substrate for tissue engineering, RSC Advances 3 (2013), pp. 6286-6289.

DOI: https://doi.org/10.1039/C3RA40408K

[33] L. Russo, T. Russo, C. Battocchio, F. Taraballi, A. Gloria, U. D'Amora, R. De Santis, G. Polzonetti, F. Nicotra, L. Ambrosio, L. Cipolla, Galactose grafting on poly $(\varepsilon-$ caprolactone) substrates for tissue engineering: a preliminary study, Carbohydrate Research 405 (2015), pp. 39-46. DOI: https://doi.org/10.1016/i.carres.2014.07.027

[34] R. De Santis, U. D'Amora, T. Russo, A. Ronca, A. Gloria, L. Ambrosio, 3D fibre deposition and stereolithography techniques for the design of multifunctional nanocomposite magnetic scaffolds, J Mater Sci Mater Med 26(10) (2015) 250. DOI: https://doi.org/10.1007/s10856-015-5582-4

[35] M. Domingos, A. Gloria, J. Coelho, P. Bartolo, J. Ciurana, Threedimensional printed bone scaffolds: The role of nano/microhydroxyapatite particles on the adhesion and differentiation of human mesenchymal stem cells, Proc. Inst. Mech. Eng. H. 231 (2017), pp. 555-564.

DOI: https://doi.org/10.1177/0954411916680236

[36] M. Martorelli, P. Ausiello, R. Morrone, A new method to assess the accuracy of a cone beam computed tomography scanner by using a non-contact reverse engineering technique, Journal of Dentistry 42 (2014), pp. 460-465. DOI: https://doi.org/10.1016/i.jdent.2013.12.018

[37] M. Martorelli, C. Pensa, D. Speranza, Digital photogrammetry for documentation of maritime heritage, Journal of Maritime Archaeology 9 (2014), pp.81-93. DOI: https://doi.org/10.1007/s11457-014-9124-x

[38] M. Calì, D. Speranza, M. Martorelli, Dynamic spinnaker performance through digital photogrammetry, numerical analysis and experimental tests, Advances on Mechanics, Design Engineering and Manufacturing, Lecture Notes in Mechanical Engineering. B. Eynard, V. Nigrelli, S. Oliveri, G. Peris-Fajarnes, S. Rizzuti (editors). Springer, Cham, Switzerland, 2017, ISBN 978-3-319-45781-9, pp. 585-595.

[39] V. Pagliarulo, F. Farroni, P. Ferraro, A. Lanzotti, M. Martorelli, P. Memmolo, D. Speranza, F. Timpone, Combining ESPI with laser scanning for $3 \mathrm{D}$ characterization of racing tyres sections, 
Optics and Lasers in Engineering 104 (2018), pp. 71-77. DOI: https://doi.org/10.1016/j.optlaseng.2017.07.004

[40] P. Ausiello, S. Ciaramella, M. Martorelli, A. Lanzotti, A. Gloria, D. C. Watts, CAD-FE modeling and analysis of class II restorations incorporating resin-composite, glass ionomer and glass ceramic materials, Dental Materials 33(12) (2017). pp. 14561465.

DOI: https://doi.org/10.1016/i.dental.2017.10.010

[41] P. Ausiello, S. Ciaramella, M. Martorelli, A. Lanzotti, F. Zarone, D. C. Watts, A. Gloria, Mechanical behavior of endodontically restored canine teeth: Effects of ferrule, post material and shape, Dental Materials 33(12) (2017). pp. 1466-1472.

DOI: https://doi.org/10.1016/i.dental.2017.10.009

[42] F. Caputo, A. De Luca, A. Greco, S. Maietta, M. Bellucci, FE simulation of a SHM system for a large radio-telescope, International Review on Modelling and Simulations 11(1) (2018), pp. 5-14.

DOI: https://doi.org/10.15866/iremos.v11i1.14784

[43] A. Gloria, S. Maietta, M. Martorelli, A. Lanzotti, D. C. Watts, P. Ausiello, FE analysis of conceptual hybrid composite endodontic post designs in anterior teeth, Dental Materials 34(7) (2018), pp. 1063-1071.

DOI: https://doi.org/10.1016/i.dental.2018.04.004
[44] A. Baccigalupi, A. Liccardo, The Huang Hilbert Transform for evaluating the instantaneous frequency evolution of transient signals in non-linear systems, Measurement, Vol. 86, May 2016, pp. 1-13.

DOI: https://doi.org/10.1016/i.measurement.2016.02.018

[45] M. Giordano, P. Ausiello, M. Martorelli, R. Sorrentino, Reliability of computer designed surgical guides in six implant rehabilitations with two years follow-up, Dental Materials 28(9) (2012), pp. e168-e177.

DOI: https://doi.org/10.1016/i.dental.2012.06.005

[46] L. Angrisani, F. Bonavolontà, A. Liccardo, R. Schiano Lo Moriello, On the use of LORA technology for logic selectivity in MV distribution networks, Energies, 11(11) (2018), 3079, 34 pages.

DOI: https://doi.org/10.3390/en11113079

[47] L. Angrisani, F. Bonavolontà, A. Liccardo, R. Schiano Lo Moriello, F. Serino, Smart power meters in augmented reality environment for electricity consumption awareness, Energies, 11 (9) (2018), 2303, 17 pages. DOI: https://doi.org/10.3390/en11092303

[48] X. Xin, A. Borzacchiello, P. A. Netti, L. Ambrosio, L. Nicolais, Hyaluronic-acid-based semi-interpenetrating materials, J Biomater Sci Polym Ed. 15(9) (2004), pp. 1223-1236. DOI: https://doi.org/10.1163/1568562041753025 